\title{
Circuitos de uso de crack na região central da cidade de São Paulo (SP, Brasil)
}

\author{
Crack usage circuits in the downtown area \\ of the city of São Paulo (SP, Brazil)
}

Luciane Raupp ${ }^{1}$

Rubens de Camargo Ferreira Adorno ${ }^{1}$

${ }^{1}$ Faculdade de Saúde Pública, Universidade de São Paulo. Av. Dr. Arnaldo 715, Cerqueira César. 01246-904 São Paulo SP. lucianeraupp@usp.br
Abstract Although drug usage has been prevalent since the dawn of humankind, drug abuse has currently escalated alarmingly and can be characterized as a public health problem. The spread of "crack," a drug derived from cocaine paste, is worsening the situation by aggravating the social damages and harming the health of users. An ethnographic study was conducted in downtown São Paulo, SP (Brazil) in locations where crack is sold and used in order to establish the impact of the spread of this drug in the daily life of users. A field diary was used to record the observations and informal dialogues with the people who circulate in the location under scrutiny. The results of this study show the circuits covered by the users, their dynamics and the complex relationships with other social players, based on permanent tension, involving the practice of violence in which the users are both victims and perpetrators. The study also suggests the importance of other factors such as the history of the region in question, the public policies, economic questions and the lack of social investments and public health. It is suggested that the advanced degree of degradation of the region researched is not only the result of the people and activities practiced in the area, but also mainly of the urban process that led to such a social scenario. Key words Crack usage, Ethnography, Public health
Resumo Apesar de o uso de drogas ser uma prática presente desde os primórdios da humanidade, atualmente o seu abuso adquiriu dimensões preocupantes, configurando-se como um problema de saúde pública. O surgimento do crack, droga derivada da pasta de coca, agravou esse quadro ao aumentar os danos sociais e à saúde dos usuários. Visando conhecer o impacto de sua inserção no cotidiano dos usuários, foi realizado um estudo etnográfico em locais de venda e uso de crack na região central da cidade de São Paulo (SP, Brasil). Foi utilizado um diário de campo para registrar as observações e os diálogos informais efetuados com as pessoas que circulavam no local estudado. Os resultados apontaram os circuitos percorridos pelos usuários, suas dinâmicas e as relações que estabelecem com outros atores sociais, as quais são permeadas por permanente tensão, envolvendo a prática de atos violentos nos quais os usuários são tanto agressores quanto vítimas. O estudo também sugere a importância de outros fatores como a história da região pesquisada, as políticas públicas, questões econômicas e ausência de investimentos sociais e em saúde pública. Sugere-se que o alto grau de degradação da região pesquisada não seria consequência apenas das pessoas e atividades exercidas no local, mas principalmente do processo urbano que gerou tal quadro social.

Palavras-chave Crack, Etnografia, Saúde pública 


\section{Introdução}

A um transeunte desavisado ou algum turista em visita ao Centro da cidade de São Paulo, ruas como Helvetia e Gusmões passariam facilmente despercebidas, dados seus poucos atrativos arquitetônicos, comerciais ou sua escassa importância histórica e cultural. Entretanto, a depender do dia e horário em que esse suposto transeunte passasse por tais locais, provavelmente se espantaria ante a estranha movimentação e o comércio que acontece, como muitas vezes a imprensa tem propagado, "à luz do dia" nesses espaços, sentindo-se coagido a sair de tais ruas, visando a sua autoproteção.

Nascida nas imediações de onde, no passado, vivia a aristocracia paulistana, instalada nos bairros da Luz e dos Campos Elíseos, a "Cracolândia" (forma pela qual essa região é conhecida) ganhou no imaginário da cidade o status de "nação independente" em meados da década de 1990, época na qual a principal droga vendida nessa área, o crack (derivado da pasta de coca), obteve rápida propagação.

Já popular nos EUA desde a década de 1980, no Brasil o crack surgiu em meados de 1988, em bairros da periferia de São Paulo. Em 1991, já se podia observar uma intensa procura pela droga na região central da cidade, especialmente no bairro da Luz; e em 1993, seu consumo alcançava grandes dimensões. Entre 1995 e 1997, a prevalência de uso aumentava de $5,2 \%$, antes de 1989 , a $65,1 \%$, tornando o crack e a cocaína as principais drogas consumidas na cidade. Em 2005', a prevalência de uso na vida de crack correspondia a $0,7 \%$ da população, equivalente a 381 mil pessoas, o dobro do valor registrado em 2001.

Passados vinte anos do surgimento do crack no mercado ilegal brasileiro, constata-se que sua presença trouxe maior complexidade e dificuldades adicionais a vários segmentos que, direta ou indiretamente, são afetados pela disseminação do seu uso. De questões de planejamento urbano e segurança pública aos programas de atenção, pesquisa e políticas voltadas a tal público, as particularidades dos contextos, significados e formas de uso de crack trouxeram desafios ainda à espera de respostas capazes de fornecer orientações mais efetivas que a simples repressão.

\section{Método}

Visando colaborar para o entendimento desse público sob um viés qualitativo, este estudo bus- cou caracterizar o uso de crack como uma prática inserida no cotidiano do Centro da cidade de São Paulo, à qual se articula uma rede de outras questões, comportamentos e atores associados. Para tanto, buscou-se descrever os circuitos percorridos pelos usuários e suas dinâmicas. $\mathrm{O}$ conceito de circuitos ${ }^{2}$ visa compreender a inserção dos pesquisados na paisagem urbana por meio da etnografia dos espaços por onde circulam, de seus pontos de encontro e conflito e de seus parceiros.

A observação participante foi o método utilizado para proceder à etnografia dos circuitos estudados. Nesse método, o pesquisador deve passar longos períodos convivendo com os grupos estudados; acompanhar de perto suas atividades diárias, desde as mais triviais até as mais especiais; aprender a língua nativa; absorver valores e sentimentos do grupo, observando cuidadosamente o que as pessoas fazem e dizem ${ }^{3}$. Sobretudo, seu papel compara-se ao de um intérprete entrando em um mundo estranho e tentando compreendê-lo do ponto de vista de seus integrantes ${ }^{4}$.

O trabalho de campo ocorreu através da inserção dos pesquisadores no cotidiano de trabalho de uma organização não governamental (ONG) que atua na região aplicando estratégias de redução de danos dirigidas a usuários de cra$c k$. Por meio das idas a campo com a equipe da ONG, foi possível uma aproximação aos usuários em seus momentos de socialização e/ou uso da droga nas principais ruas nas quais isso ocorre.

A coleta de dados ocorreu durante seis meses (de agosto 2007 a janeiro de 2008), consistindo na realização de observações e conversas informais com usuários e outros atores presentes nos locais de pesquisa, registradas em diário de campo. A análise dos dados baseou-se na compreensão e elaboração das informações coletadas no diário de campo. Ao longo deste artigo, o material empírico coletado estará presente através da transcrição de trechos de observações e diálogos registrados no diário de campo.

\section{Resultados}

\section{O Centro de São Paulo e a existência da "Cracolândia"}

O fato de São Paulo ter sido a primeira cidade a registrar a presença de crack no país, somado à existência de uma região reconhecida pela sua venda e uso, com toda uma rede informal de serviços e pessoas interligadas a tal atividade, 
sugere a amplitude da problemática nesse contexto. A existência da "Cracolândia" alude ao fato de o espaço urbano não se constituir apenas como espaço geográfico, mas antes de tudo como espaço relacional onde se constroem relações diversas de troca, lazer, identidade ${ }^{5}$. Tais relações interligam-se às funções e práticas desenvolvidas nos locais, as quais, muitas vezes, acabam por caracterizá-los.

A região que abriga a "Cracolândia" foi palco de diferentes experiências urbanas, caracterizando-se por funções e usos de seu espaço relacionados à própria história da cidade. Localizada no chamado "Centro Novo", integrava os circuitos de lazer das elites paulistanas nas primeiras décadas do século passado, quando o Centro era espaço privilegiado de negócios, compras e lazer das classes altas.

Essa configuração da área começou a mudar na segunda metade do século XX, quando grandes empresas, bancos, lojas de artigos de luxo e grandes hotéis deslocaram-se para outras áreas da cidade. Nesse processo, ocorreu um deslocamento da elite, a qual passou a frequentar as novas centralidades que afloravam no compasso do crescimento da metrópole ${ }^{6}$. Consequentemente, a área central iniciou um processo de desvalorização e popularização que acarretou mudanças e diversificação nos atores e atividades locais, com o surgimento de formas de ocupação estratégicas ligadas à busca pela sobrevivência ${ }^{7}$.

A desvalorização da área central relacionouse a vários fatores, tais como a popularização dos automóveis e a consequente construção de novas vias de interligação entre as diversas áreas da cidade. A partir de então, ao Centro foi imputado principalmente o papel de nó de ligação e de passagem entre as diferentes regiões da capital.

Além disso, à migração das elites seguiu-se o deslocamento da intensa atividade imobiliária até então existente para outras áreas, promovendo um processo de desvalorização imobiliária e a diminuição do número de residentes. Devido à existência de muitos domicílios vazios, existem hoje prédios inteiros invadidos por pessoas de baixa renda, situação que constitui um ponto de conflito entre os moradores e a governança local. Além desses, predominam os cortiços, que constituem um significativo meio de habitação, nos quais aglomeram-se famílias, a grande maioria oriunda de outras regiões do país, vivendo muitas vezes em condições precárias e insalubres ${ }^{6}$. Proliferaram também pequenos hotéis surgidos nas proximidades da antiga rodoviária, os quais, após o deslocamento desta para a Marginal Tie- tê, passaram a ser cada vez mais frequentados por prostitutas, traficantes e usuários de drogas.

Como consequência do processo de esvaziamento imobiliário, muitas ruas onde tradicionalmente havia uma ocupação mesclada entre comércio e uso residencial encontram-se hoje inteiramente vazias depois do horário comercial e nos fins de semana, o que constitui um sério agravante às condições locais de segurança. Em algumas ruas houve uma apropriação do espaço público por vendedores e usuários de drogas, constituindo o que é considerado hoje um dos maiores problemas do Centro de São Paulo.

\section{Políticas de revitalização do Centro e seus efeitos sobre os usuários de crack}

Atualmente, o Centro é uma área de grande visibilidade e importância política na cidade, devido ao fato de sua recuperação ser uma das prioridades da atual gestão municipal, a qual possui uma política em curso desde a década de 1980 dedicada à transformação do bairro da Luz em uma área cultural. Como resultado, pessoas das classes médias e altas têm frequentado a região para práticas de consumo cultural em instituições culturais e prédios históricos restaurados ou recémcriados da região. No entanto, apesar desse novo afluxo de pessoas, a recuperação da área não se deu por completo e contrasta com o entorno da região, ainda de grande ocupação popular ${ }^{8}$.

Visando incidir sobre esse "outro lado" da Luz, um projeto da atual Prefeitura, intitulado "Nova Luz", desencadeou uma série de intervenções repressivas, objetivando ao controle e à expulsão dos grupos populares que circulam na região. Entre essas ações, a "Operação Limpa" de 2005, a qual procurava preparar o terreno para a consolidação de processos de requalificação urbana no bairro ${ }^{8}$, foi a que atingiu de forma mais direta os usuários de crack. Nessa operação, vários estabelecimentos, particularmente pequenos hotéis que se prestavam ao comércio e uso de drogas, foram interditados, e os usuários expulsos das ruas que frequentavam, ocasionando modificações nos circuitos de uso de crack. Um trecho do diário de campo ilustra os efeitos ainda visíveis dessas ações:

$\mathrm{Na}$ volta do trabalho de campo, passamos pelas ruas Triunfo e dos Andradas. Uma pessoa que nos acompanha comenta que ali era o "epicentro da Cracolândia” há uns 2/3 anos atrás. A região agora está totalmente reconfigurada. Nas ruas onde havia amplo consumo de crack, não se vê nenhum 
usuário (pelo menos de dia). Enquanto caminhamos, observo os hotéis interditados, muitos dos quais têm as portas lacradas com tijolos e o carimbo "local interditado". Um colega comenta ser isso efeito da operação "Limpa".

Em um dossiê de denúncia de violações dos direitos de grupos que residem ou transitam pelo Centro, elaborado pela organização Centro Vivo", a "Operação Limpa" foi qualificada como violadora de uma série de direitos fundamentais desses grupos. Além disso, segundo o dossiê, teria tido como efeito apenas o deslocamento das pessoas que transitavam pela região, as quais passaram a procurar outras ruas, praças e mocós nas redondezas. Nesse mesmo documento, é denunciada a atuação truculenta da polícia militar e da guarda civil metropolitana nas ações de expulsão dos moradores de rua.

O trecho a seguir, extraído do diário de campo, demonstra a continuidade de ações inspiradas na "Operação Limpa", dessa vez com o suporte de funcionários da limpeza urbana. Vê-se também a revolta de um morador de rua pela truculência das abordagens:

Saímos caminhando para o outro extremo da Praça Princesa Isabel e passamos por um rapaz de aproximadamente 25 anos que nos vê e grita, dizendo:

- Só aparecem depois que acaba o rapa! Quando os moradores de rua precisam, não aparece ninguém para ajudar! Um dia vamos acabar matando todo mundo!

Inicialmente nos assustamos com tamanha hostilidade, mas resolvemos tentar conversar. $O$ jovem relata, muito exaltado, que na noite anterior foram abordados por policiais acompanhados de funcionários da limpeza urbana que os chutaram enquanto estavam dormindo "sem fazer mal a ninguém”, mandando-os sair dali. Diz que isto é um absurdo porque são usuários de drogas, mas o uso não é mais ilegal, então ninguém pode prendêlos por isso:

- Já tamo fudido e ainda por cima aparece essa gente aqui pra nos infernizar!

Apesar da mudança na lei de drogas no país (a qual despenalizou a conduta criminal dos usuários ao dispensar a necessidade de o consumidor flagrado com entorpecentes ir à delegacia), os relatos dos moradores de rua apontam para o que poderia ser denominado de um tratamento diferenciado para esse público. No próximo trecho, um jovem usuário se refere à atuação da polícia:

A esquina entre as ruas Barão de Piracicaba e Helvetia está lotada de usuários, talvez porque esteja chovendo e ali há a proteção de marquises.
Aglomeram-se dos dois lados da rua, em movimentação constante. Observamos o movimento da porta de um bar e, enquanto isso, conversamos com dois adolescentes que estão perto de nós, sentados na soleira de uma porta, com pedras de crack na mão. Pergunto ao mais jovem porque estão "de canto" e ele diz que é porque ali é mais fácil para ficar de olho na polícia. Explica que, quando estão junto à maioria dos usuários, só veem a polícia quando esta já está perto, não tendo mais para onde fugir. Um colega da ONG pergunta:

- Mas a polícia não fica cabreira de chegar quando tem muita gente?

- Fica nada! Vão chegando direto! Antes tava a operação Pente Fino e levavam todo mundo. Se tava com droga ia preso.

Em nossas idas a campo observávamos que quando havia uma presença policial mais constante, ou seja, não restrita apenas à passagem de viaturas em frente aos usuários, ela se dava geralmente em ruas como Helvetia, Gusmões, Barão do Triunfo, General Osório. Nessas ações, os policiais instalavam postos itinerantes ou ficavam em guarda no local por várias horas. Sua presença provocava uma dispersão temporária dos usuários, os quais se deslocavam para fumar em outros pontos de seus circuitos ou ficavam circulando até o movimento voltar ao normal. Conforme a fala de um funcionário da ONG que acompanhávamos:

- Eles [os policiais] só espalham a galera; depois volta tudo pro mesmo lugar.

Quando essas ações policiais ocorriam, víamos usuários agrupados, algumas vezes entre cinquenta/sessenta pessoas de todas as idades, em algum ponto secundário de seus circuitos, como, por exemplo, a Praça Júlio Prestes. Podiam também ser vistos em grupos menores ou em duplas, parados ou circulando, em ruas que costumavam ser mais frequentadas por esse público na década de 1990, tais como as ruas Aurora e Vitória. Nesses momentos, a aproximação podia ser mais tensa que o normal devido à grande concentração de pessoas ou ao fato de os usuários estarem com pressa, em busca de locais mais seguros, não estando, portanto, disponíveis para abordagens, como se apreende do trecho a seguir:

Nos aproximamos para distribuir insumos a quatro jovens que estão sentados em um degrau, ao lado de uma construção, na Rua Vitória. Olhamnos desconfiados e não dão muita conversa. Entre eles se destaca uma jovem que se mostra especialmente desconfiada, parecendo incomodada com a nossa presença. Não aceita insumos e não responde quando nos dirigimos a ela. 
Além do caráter nitidamente higienista das ações de expulsão dos "grupos indesejáveis" do bairro da Luz, a associação entre moradores de rua e uso de drogas colabora para exacerbar os fortes estigmas associados a estes. Assim, estar na rua é compreendido como sinônimo de ser "drogado" ou ainda um elemento mais perigoso, um "viciado em crack", o que acaba estendendo aos moradores de rua as representações de periculosidade ligadas aos usuários ${ }^{10}$.

Embora muitos moradores de rua não sejam usuários de crack, o fato de ser uma droga aparentemente barata colaborou para torná-la popular, expondo pessoas que já sofrem cotidianamente com a exclusão a uma exploração comercial cruel.

Nas ruas com maior movimento de usuários, era visível que aproximadamente $90 \%$ dos usuários eram "pessoas em trânsito pela rua" ${ }^{10}$, expressão que ressalta o caráter de transitoriedade do estar na rua. Isto é particularmente verdade no caso do uso de crack, pois nas trajetórias perpetradas pelos usuários jovens, a passagem para morador de rua pode ser precedida de um período de idas e vindas entre sua comunidade e as ruas do Centro, com a tendência a permanecer períodos cada vez maiores na rua na medida em que se aprofunda a relação do sujeito com a droga. O relato a seguir traz a história de transição à rua de um usuário com quem conversamos:

Z. conta que fazia faculdade de Jornalismo e já fumava crack, mas conseguia levar as duas coisas ao mesmo tempo, até chegar a um ponto em que "desandou", há mais ou menos oito meses, e acabou parando na rua. Diz que tem vontade de parar com as drogas porque gostaria de voltar a estudar. Sobrevive vendendo cachimbos para fumar crack, que confecciona a partir de antenas usadas.

Em outro momento do trabalho de campo, observamos um casal, que anteriormente tínhamos visto de passagem, comprando crack, e que agora parecia em situação de rua:

Observo um casal jovem, aparentando uns vinte anos de idade, o qual eu vira há uns dias pelas ruas da Cracolândia e me chamara a atenção pela boa aparência, especialmente da menina, bonita e bem arrumada. Hoje (um dia de inverno, frio) estavam deitados na grama da Praça Princesa Isabel, cobertos por um cobertor semelhante ao dos demais moradores de rua locais.

Já no caso das crianças, algo diferente parece ocorrer. Segundo Adorno, a droga não pode ser apontada necessariamente como a causa da ida das crianças às ruas, pois geralmente é quando já estão inseridas nesses circuitos que entram em contato com elas: Uma vez imersas na experiência da rua, essas crianças iniciam-se em círculos de sociabilidade e socialização, em que o uso de drogas irá se colocando como ritual de iniciação e aceitação nos grupos ${ }^{10}$. Segundo o autor, o uso do crack é uma forma de ficar mais esperto, ter coragem para enfrentar situações complexas, como o roubo, inserindo-se assim na gama de comportamentos que compõe um estilo de vida inerente à vivência da rua. As propriedades químicas do crack ajustam-se perfeitamente ao estilo requerido pela rua, onde se vive pelo prazer do instante, daí a compulsão para fumar uma "pedra" atrás da outra.

No estágio atual dos projetos de revitalização do Centro, órgãos públicos estão sendo transferidos para a região e incentivos fiscais oferecidos a empresas dispostas a investir no local. Para tanto, uma grande região está em processo de desapropriação a fim de "limpar a área" para novos investidores, abarcando todo o perímetro formado pelas avenidas Rio Branco, Duque de Caxias, Cásper Líbero, Ipiranga e Praça Alfredo Issa. No início de 2008, uma ida a campo surpreendeu os pesquisadores com o início das demolições:

Entramos na Rua Santa Efigênia e a percorremos até a esquina entre Gusmões e a Avenida Rio Branco, onde paramos, surpresos com o cenário que vimos. Um colega da ONG comenta:

- Nossa, tinha um monte de coisas aqui!

Com uma máquina fotográfica, registramos as cenas da demolição de antigos hotéis que ocupavam um amplo terreno de esquina onde agora não há mais nada. Mais à frente, dois terrenos de esquina com seus prédios, possivelmente de hotéis, estão também totalmente demolidos. No que era uma parede de azulejos ainda visivel entre os escombros foi feita uma pichação que questiona essas ações com a frase: "Revitalização ou higienização?" Denunciando o paradoxo - ou a inefetividade - de tais ações há um casal de usuários sentados em frente a essa parede, fumando em meio aos escombros.

No primeiro semestre de 2008, apesar das ações de fechamento de hotéis, bares e da prisão de suspeitos, a região continuava a ser frequentada por traficantes e usuários de drogas. Durante o período da coleta de dados, ações da polícia eram ainda frequentes sem, no entanto, apresentar uma continuidade capaz de produzir efeitos duradouros. Apesar disso, propagandas da gestão municipal afirmavam o "fim da 'Cracolândia', negando a existência de usuários pelas ruas do Centro. 


\section{A "Cracolândia" como um "campo de forças"}

O fato de o fim da "Cracolândia" ser uma importante meta política reflete as aspirações de grande parte dos habitantes da cidade, os quais assistiram ao aumento da violência urbana e do tráfico de drogas na região. Uma pequena parte dessas pessoas está em interação diária com os usuários de crack e possui diferentes visões sobre estes e as políticas de "limpeza" da região, além de interesses diferenciados. A seguir, destacaremos trechos que apontam para algumas facetas das relações entre os usuários de crack e os habitantes das pensões, os comerciantes e alguns traficantes locais.

A coexistência entre os usuários de drogas e os habitantes das pensões da região se dá de forma aparentemente pacífica, desde que respeitados os limites que separam um grupo do outro. Nas principais ruas onde havia uso de crack, como a Helvetia, existem pensões populares em frente às quais podia-se sempre avistar residentes com suas famílias, conversando ou ouvindo música, e parecendo não se importar com os usuários por perto. Grande parte desses moradores são migrantes provenientes do Nordeste do país.

A seguir, um trecho de uma conversa ocorrida durante o trabalho de campo com um homem de aproximadamente 50 anos, natural do estado do Maranhão e residente na região há vinte anos, demonstra algumas regras implícitas a essa coexistência:

Entro em um bar para pedir informações sobre uma rua e um senhor se oferece para me levar até o local. No caminho passamos por jovens fumando crack. Pergunto se ele considera a região perigosa devido à presença dos usuários. Ele responde:

- Não, não é não! Eles são Nóia! Ficam por ali usando a droga deles e não mexem com ninguém. Pelo menos comigo ninguém se mete! E "ai" deles se se meterem! Não são loucos!

Diz que o perigo é só se passar por ali à noite, após as 21h:

- Dai é perigoso porque não passa quase ninguém nas ruas, daí eles podem tentar assaltar.

Os interesses em jogo para os vários traficantes que circulam na "Cracolândia" são evidentemente de cunho econômico. Por toda a região há pontos de venda, alguns exclusivos de crack e outros que vendem também outras drogas. Alguns são fixos, situados em pequenos hotéis ou em prédios onde residem traficantes. Um destes nos foi mostrado por um usuário, era um prédio invadido onde aproximadamente $80 \%$ dos residentes seriam traficantes.
Outra forma bastante comum de comércio da droga é através de pessoas que circulam pelas ruas onde há uso de crack. Entre esses vendedores há os que são usuários - vendem e consomem crack - e os não usuários que estão ali por motivos estritamente comerciais. Muitos dos que avistávamos eram mulheres entre 25 e 40 anos de idade, visivelmente diferentes das consumidoras frequentes de crack (mais bem vestidas e com aparência saudável). Algumas andam em companhia de crianças. Nunca fomos abordados por traficantes não usuários, o que talvez reflita maior cautela nesse grupo.

Entre os usuários que vendem crack para sustentar seu consumo há, no mínimo, dois tipos de estratégias empregadas para a consecução da droga. Uma delas nos foi explicitada por um policial em campo, o qual, ao falar sobre a ineficácia das ações policiais na área, expõe sua opinião sobre os usuários e suas formas de sobrevivência:

- Não adianta! Eles vão continuar por aqui porque é muito fácil pra eles, porque tem tudo o que precisam: dormem em albergues, ganham comida e têm crack. Por exemplo, eles compram uma pedra por 20,00 e, dessa, fazem quatro pedras para vender por 10,00 cada; então acabam saindo no lucro.

Outra forma de comércio de crack pelos usuários é quando trabalham para um traficante local, ajudando-o a vender parte de seu produto e recebendo drogas ou dinheiro em troca. As relações entre os usuários e os traficantes podem ser truculentas e, por vezes, de cunho exploratório, como sugere o trecho a seguir:

Passando pela Rua Gusmões encontramos uma usuária de 23 anos de idade sentada em meio a uma demolição. Chorava muito relatando fortes dores nas pernas (dizia ter Artrite Reumatóide). Apesar da insistência da equipe e de um amigo, não queria ir embora porque uma traficante the devia 50,00 e, segundo seu relato, se fosse embora nunca mais veria "a cor do dinheiro". Em um determinado momento seu amigo foi até a traficante pedir o dinheiro, the explicando a situação. Voltou apenas com o suficiente para pegar o metrô de volta para casa, o que a deixou ainda mais revoltada. Horas depois passamos novamente pelo local e a jovem continuava ali, sentada no chão.

Uma particularidade dos circuitos de uso de crack do Centro refere-se à interação que os usuários têm com a comunidade local, especialmente com os comerciantes. Diferentemente do que ocorre nas periferias, onde os locais de uso são mais reservados, nas ruas onde pesquisávamos, os usuários podiam facilmente ser vistos fumando crack ao lado de estabelecimentos comerciais. 
Este fato fazia com que os comerciantes e seus clientes convivessem com as dinâmicas dos locais de uso, as quais podiam envolver ruidosas disputas ou brigas entre usuários, como presenciamos mais de uma vez em campo, além de furtos e assaltos na redondeza. Por isso, tais relações eram tensas ou violentas, podendo inclusive envolver a contratação de pessoas para manter os usuários afastados, como ocorreu em ruas como Vitória, Andradas ou Gusmões, onde o uso era frequente na época de início da "Operação Limpa".

Durante o trabalho de campo, era comum ouvirmos comentários como: "Esses aí não têm mais jeito!" ou reclamações sobre os usuários por parte dos transeuntes ou dos comerciantes que espiavam de suas portas o movimento. Alguns usuários não se importavam com tais reações, encarando jocosamente a situação, como no episódio relatado a seguir:

Passo próximo à Praça da República e observo dois jovens moradores de rua sentados na porta de um caixa eletrônico. Um deles ri e, olhando maliciosamente para o companheiro, fala para um homem que sai do caixa eletrônico:

- Dá dinheiro pra nós comprar crack pra fumar no cachimbo!

Uns transeuntes ouvem e, indignados, comentam:

- É, é pra isso mesmo que eles querem, dinheiro!

- Pelo menos esses aí admitem!

No entanto, entramos também em contato com usuários que afirmavam ter vergonha de seu uso, como uma mulher de 30 anos acostumada a fumar apenas à noite por ter receio de ser vista usando drogas na rua. Muitos admitiam querer parar de usar crack, inclusive pediam ajuda para tanto.

Dois episódios, um deles ocorrido em uma das esquinas de maior movimento de usuários e outro em uma rua comercial onde foi feito um buraco em uma parede de um prédio abandonado que passou a servir de refúgio para muitos usuários, demonstram a opinião dos comerciantes e algumas das estratégias que utilizam para afastar os usuários. Descreveremos as situações a partir da reprodução de trechos do diário de campo:

Chegamos por volta das 17 horas na Alameda Barão de Piracicaba e avistamos vários usuários, contudo algo diferente está ocorrendo: um homem negro, forte e bem vestido caminha de um lado a outro da rua gritando com os usuários para que saiam dali: "vazem!". Manda deixarem o pessoal do comércio trabalhar (por ali tem uns bares e uma agência de turismo que faz excursões para o norte do país). Fala muito alto e é bem agressivo.
Diz para a equipe que sabe que eles estão ali para ajudar "o seu pessoal" e que está tentando organizá-los, pois não os quer pelas esquinas de dia, atrapalhando o pessoal do comércio. Uma adolescente, sorrindo,comenta:

- Ele é do Comando!

Perguntamos:

- Que "Comando", da polícia?

- Não, não, do PCC [Primeiro Comando da Capital].

- Ele vende crack?

- Vende, vende. Ele não quer que os Nóia fiquem aqui de dia. Mas de noite libera pra nós.

- E vocês obedecem ele?

- Claro, claro! Tem mais uns 20 deles por aí. A gente quer é fumar pedra!

Nesse episódio, subentende-se uma possível aliança entre os comerciantes e o comando do tráfico no local, visando à manutenção dos negócios de ambos. Além disso, verifica-se também a existência de uma rede organizada em torno da venda de crack na região. Cabe destacar a passividade dos usuários, os quais obedecem prontamente às ordens do traficante.

No trecho a seguir, um temido segurança, contratado pelos lojistas da região que atua ali há anos, é visto dando um soco na cabeça de uma adolescente usuária, mandando-a sair dali. Quando questionado sobre seu ato, nega e nos ameaça. Em meio à discussão, um senhor de meia idade, dono de alguns estabelecimentos comerciais, surge em defesa do segurança. No diálogo a seguir, a opinião de ambos sobre os usuários é explicitada:

Surge um senhor que se apresenta como dono de várias lojas na área. Diz que, como nós, também já teve pena dos usuários e tentou ajudá-los oferecendo trabalho, mas acabou desistindo. O segurança, reforçando a fala do comerciante, diz que não temos noção do que os usuários são capazes de fazer. Usando a menina na qual bateu como exemplo, afirma que ela assalta qualquer um que passar por ali, inclusive idosos. O comerciante, ao ver um usuário passar de bicicleta, exclama:

- Pergunta se eles querem trabalho! Tá vendo esse ai? Esses dias tava com a cara toda queimada porque tava roubando fio de luz pra vender e trocar por droga. Ofereci pra ele trabalhar aí na obra e pergunta se ele ficou um dia?! diz:

O segurança, apontando para um adolescente,

- Tá vendo aquele ali? Pergunta quantos anos ele tem?

- Não sei, uns 10/12 anos.

- Não, 16! Não cresceu por causa da droga; prefere ficar fumando crack! 
- Eles são ruins por natureza! Muitos têm famílias que os querem de volta, mas eles preferem ficar por aqui se matando!

O conteúdo generalista e negativo das opiniões do comerciante e do segurança sobre os usuários serve para justificar a violência que lhes é imposta, como se todos os seus direitos fossem anulados porque usam drogas. Cabe destacar que no dossiê de denúncias citado anteriormente a mesma violação de direitos foi imputada às ações de agentes do poder municipal no intuito de "limpar o Centro da degradação", conceito que, nesse caso, é estendido às pessoas e atividades exercidas nesses espaços, e não ao processo urbano que gerou tal quadro social ${ }^{5}$.

Ambos os episódios descritos, juntamente com a discussão sobre as políticas municipais para a região, apontam para a existência de um "campo de forças" nos circuitos de uso, no qual os usuários e suas práticas seriam apenas uma parte da teia de relações e interesses existente. Nessa "confusão de idiomas"11 podemos reconhecer diferentes formas de ocupar, projetar e significar o espaço em questão, as quais remeteriam a distintas estruturas de significado que organizariam a ação e a visão de mundo de cada um dos atores sociais. Segundo Geertz ${ }^{11}$, para compreender tal complexidade, o primeiro passo seria identificar cada um dos quadros interpretativos subjacentes ao discurso dos atores em disputa, deparando-se assim com uma multiplicidade de estruturas conceituais complexas sobrepostas ou relacionadas umas às outras.

Seguindo esse caminho, compreende-se que tanto a Prefeitura como os comerciantes têm interesses específicos sobre o espaço estudado, o qual é estratégico para a consecução de seus objetivos (comerciais/financeiros para os comerciantes e políticos/econômicos/eleitorais para a Prefeitura). Portanto, os usuários são interpretados como obstruções ao alcance de tais metas, tendo de ser expulsos para liberar a área para outros cidadãos/consumidores/eleitores. Nesse processo, alegações de preocupação com sua saúde ou condições psíquicas serviriam apenas como justificativas morais para as ações de "limpeza", dado que nenhuma política específica foi posta em prática visando melhorar suas condições.

No tocante às ações da polícia como um agente a serviço do poder público, pode-se compreendê-las como articuladas a este, servindo como instrumento para o alcance de suas metas. Nesse sentido, também responderia às solicitações da sociedade, a qual, em sua maioria, tem uma visão intolerante e fóbica a respeito dos usuários de drogas e das ruas do Centro, compreendendo-as como locais do crime à espreita e do tráfico de drogas, devendo ser evitadas a qualquer custo, articulando-se como uma das soluções mais requisitadas o aumento e o endurecimento do policiamento. Além disso, interesses econômicos estariam em jogo para alguns agentes da polícia que aufeririam lucros com o tráfico, conforme relatos de comerciantes e usuários.

Quanto aos traficantes, a alusão a uma organização subjacente ao tráfico local aponta para uma complexidade ainda maior, inerente às grandes redes de tráfico, com seus braços internacionais e colaboradores dentro dos espaços oficiais. Contudo, paralelamente a tal organização subsistem inúmeros microtraficantes que vendem drogas para garantir sua subsistência, assegurar seu suprimento de crack, ou ambos, sendo estes mais visíveis e também mais expostos às consequências dessa prática ilegal. Apesar dos riscos desse tipo de comércio, e a despeito dos julgamentos morais pertinentes, é esse tipo de economia informal - entre as tantas outras que coexistem nas ruas da região central - que permite a essas pessoas adquirir o mínimo para sua sobrevivência em face de sua situação de vulnerabilidade social ${ }^{12}$.

Por fim, no tocante aos usuários, foi o próprio contato com eles que nos alertou sobre o perigo das generalizações, dadas as suas precárias condições sociais. Como vimos no relato do comerciante e de seu segurança, sobre os usuários é lançado um olhar uniformizador, ressaltando a dependência química e suas consequências, principalmente a violência, descartando assim qualquer possibilidade de singularidade ou fatores contextuais associados aos seus comportamentos.

Sem dúvida, o crack é uma substância capaz de suscitar um alto grau de "fissura", compreendida como um desejo incontrolável de usar repetidamente a substância. Segundo Pais ${ }^{13}$, a dependência relaciona-se à capacidade de a droga criar sensações de prazer imediato, diminuindo progressivamente a capacidade de experimentar outros prazeres e ter outros interesses. Assim, o prazer do crack não é um prazer que se soma aos outros, mas que diminui os outros prazeres. Seria justamente essa diminuição de outras fontes de atratividade o que acentuaria a dependência; primeiro transformada na única fonte de prazer e, mais tarde, constituindo um consumo obsessivo já sem prazer, mas necessário para fugir ao sofrimento e preenchendo todo o cotidiano ${ }^{13}$.

Quando nos aproximamos dos cenários onde os usuários circulam, percebemos seus padrões 
de uso de drogas - geralmente nocivos, expondo-os a uma série de riscos - mas compreendemos também seus estilos, condições de vida e a aparente escassez de outras fontes de prazer, dada a sua dura realidade. Nesse sentido, a ideia de uma categoria homogênea, capaz de abarcar todos os usuários de crack, não se sustenta, pois só uma análise que considere os indivíduos com suas trajetórias de vida, motivações e experiências, e o entendimento de seus settings, considerados como o conjunto de fatores ligados ao contexto no qual a substância é tomada, o lugar, as companhias, a percepção social e os significados atribuídos ao uso da droga, é capaz de dar conta dessa realidade complexa ${ }^{14}$.

Um episódio ocorrido em campo ilustra essa asserção:

Início da tarde. Entramos na Rua Helvetia, esquina com a Avenida Duque de Caxias e vemos um grupo de seis jovens usuários, todos moradores de rua, fumado crack. Nos aproximamos e tentamos, em vão, iniciar uma conversa, pois eles sequer nos olhavam. De repente um deles que estava em pé nos pede desculpas pela não responsividade de seus companheiros e acrescenta:

- Não leva a mal, não. Se você olhar de perto vai ver que aqui ninguém é feliz!

\section{Considerações finais}

Proceder a uma análise do cotidiano dos usuários de crack a partir da compreensão das dinâmicas dos circuitos que percorrem habitualmente visou ressaltar a importância da dimensão espacial na composição de práticas e estilos de vida.

A cidade é o palco da experiência cotidiana, suas ruas e avenidas, com seus atores e movimentos, que são, ao mesmo tempo, produto e produtores de práticas sociais ${ }^{7}$. Nesse sentido, a existência da "Cracolândia" não é fruto do acaso, mas resultado tanto dos processos de crescimento da cidade e degradação de seu Centro quanto dos rumos das políticas públicas, as quais, por omissão ou ênfase em estratégias equivocadas, não conseguiram lidar adequadamente com a emergência e propagação do uso de crack.

Buscou-se com este trabalho apontar algumas facetas da diversidade presente no espaço estudado. A partir da descrição dos atores em disputa e suas formas de ocupar e significar o espaço em questão demonstrou-se que a "Cracolândia", como todo "território psicotrópico"15, cria complexas relações sociais em seu entorno. Tais relações tendem a materializar-se em práticas de oposição aberta aos usuários, mas também evocam a necessidade de adaptação por parte da comunidade, a qual por vezes consegue auferir algumas vantagens da situação, como no caso dos hotéis da região ou no uso político dos projetos de revitalização.

Esses projetos, que na prática são operações de expulsão de moradores de rua e usuários de crack, demonstram uma nova via de ação para lidar com o "problema da droga", dado o fracasso das ações repressivas. Como não se consegue lidar com o problema, modifica-se o espaço urbano, tornando-o menos permeável aos grupos desviantes e mais acessível ao controle social.

De forma semelhante à experiência portugue$\mathrm{sa}^{15}$, os planos de reurbanização iniciam-se por grandes demolições nas áreas consideradas degradadas como forma de exibição ritual da reconquista da rua pelo poder municipal. Dada a impossibilidade de deter a expansão do uso de drogas, a alternativa passa a ser o controle sobre seus territórios, mesmo que este seja pontual, pois os circuitos são dinâmicos e recompõem-se no mesmo ritmo das ações de expulsão.

Neste trabalho buscamos dar uma visão geral, aludindo a alguns pontos-chave dos circuitos de uso. Descrevemos locais aos quais tivemos acesso durante o trabalho de campo, restritos a algumas praças e ruas da região central da cidade. Não objetivamos esgotar essa análise, reconhecendo a existência de outros locais que compõem o itinerário dos usuários, aos quais não tivemos acesso por diversas razões: por situarem-se fora da região central (o que escapava aos objetivos e possibilidades do trabalho); por desconhecimento; ou devido ao ingresso ser restrito às pessoas pertencentes ao "pedaço"

Além disso, as ações de expulsão dos usuários de drogas da região fazem com que eles se desloquem, criando continuamente novas "Cracolândias". Por isso, toda análise dos circuitos de uso de crack se mostrará provisória e condicionada às mudanças operadas pelos usuários que seguirão buscando por espaços nos interstícios da cidade como forma de sobrevivência reativa a sua criminalização e estigmatização. 


\section{Colaboradores}

L Raupp e RCF Adorno participaram igualmente de todas as etapas da elaboração do artigo.

\section{Referências}

1. Carlini EA, Galduróz JC, Noto AR, Carlini CM, Oliveira LG, Nappo AS, MouraYG, Sanchez ZVDM. II levantamento domiciliar sobre o uso de drogas psicotrópicas no Brasil: estudo envolvendo as 108 maiores cidades do país. São Paulo: Páginas \& Letras; 2005.

2. Magnani JG. Os circuitos dos jovens urbanos. Revista Tempo Social 2005; 17(2):173-205.

3. Malinowski B. Argonautas do pacífico ocidental. São Paulo: Abril Cultural; 1978.

4. Marcus MT, Liehr PR. Abordagens de pesquisa qualitativa. In: Wood-Lobiondo G, Haber J, organizadores. Pesquisa em enfermagem. Rio de Janeiro: Guanabara Koogan; 2002. p. 122-139.

5. Silva S L. Mulheres da Luz: uma etnografia dos usos e preservação no uso do crack [dissertação]. São Paulo: Faculdade de Saúde Pública, Universidade de São Paulo; 2000.

6. Sampaio MRA, Pereira PCX. Habitação em São Paulo. Estudos Avançados 2003; 17(48):167-183.

7. Frúgoli Jr H. São Paulo: espaços públicos e interação social. São Paulo: Marco Zero; 1995.

8. Frúgoli Jr H. Roteiro pelo bairro da Luz, São Paulo. Ponto Urbe [periódico na Internet]. 2008 [acessado 2008 jun 20]: 1(1): [cerca de 2 p.]. Disponível em: http://n-a-u.org/pontourbe02/Heitor.html

9. Dossiê Centro Vivo [material disponível na Internet]. 2007 [acessado $2007 \mathrm{dez} 20$ ] [cerca de 50 p.]. Disponível em: http://dossie.centrovivo.org/Main/ HomePage

10. Adorno RCF. Os imponderáveis circuitos dos vulneráveis cidadãos: trajetórias de crianças e jovens nas classes populares. In: Lerner J, organizador. Cidadania, verso e reverso. São Paulo: Imprensa Oficial do Estado; 1997/1998. p. 93-109.

11. Geertz C. A interpretação das culturas. Rio de Janeiro: LTC; 1989.

12. Bourgois P. In search of respect: selling crack in $E l$ Barrio. New York: CUP; 1995.

13. Pais JM. Culturas juvenis. Lisboa: Imprensa Nacional/Casa da Moeda; 1999.

14. Zinberg N. Drug, set and setting: the basis for controlled intoxicant use. New Haven: YUP; 1984.

15. Fernández L, Pinto M. El espacio urbano como dispositivo de control social: territorios psicotrópicos y políticas de la ciudad. Monografías Humanitas [periódico na Internet]. 2006 [acessado 2008 jul 14]: [cerca de 15 p.]. Disponível em: http:// www.fundacionmhm.org/pdf/Mono5/Articulos/ articulo10.pdf

Artigo apresentado em 27/08/2008

Aprovado em 19/01/2009

Versão final apresentada em 20/02/2009 